\title{
Effects of Natural Radiation, PAR and Artificial Ultraviolet Radiation-B on the Ultrastructure and Histochemistry of Leaf of Oryza sativa L."
}

\author{
Sérgio L. de Almeida ${ }^{1}$, Éder C. Schmidt ${ }^{1}$, Ana C. Rodrigues ${ }^{2}$, Zenilda L. Bouzon ${ }^{3 \#}$ \\ ${ }^{1}$ Post-Graduate Program in Cell Biology and Development, Department of Cell Biology, Embryology and Genetics, Federal University \\ of Santa Catarina, Florianópolis, Brazil; ${ }^{2}$ Department of Botany, Federal University of Santa Catarina, Florianópolis, Brazil; ${ }^{3}$ Central \\ Laboratory of Electron Microscopy, Federal University of Santa Catarina, Florianópolis, Brazil. \\ Email: "zenilda.bouzon@ufsc.br
}

Received August $10^{\text {th }}, 2012$; revised September $7^{\text {th }}, 2012$; accepted September $20^{\text {th }}, 2012$

\begin{abstract}
Ultraviolet radiation-B (UVBR) affects plants in many important ways, including reduced growth rate, reduction of primary productivity and changes in ultrastructure. The rice (Oryza sativa) is one of the most cultivated cereal in the world along with corn and wheat, representing over $50 \%$ of agricultural production. In this study, we examined $O$. sativa exposed to natural radiation denominated which "ambient samples", plants cultivated which photosynthetically active radiation (PAR), denominated with PAR-only and plants cultivated with PAR + UVBR for $2 \mathrm{~h}$ per day during 30 days of cultivation in vitro. The samples were processed for electron microscopy and histochemistry analysis. PAR + UVBR caused changes in the ultrastructure of leaf of $O$. sativa, mesophyll cells, which included increased thickness of the cell wall and plastoglobuli, reduced intracellular spaces, changes in the cell contour, and destruction of chloroplast and mitochondria internal organization. The exposure to PAR + UVBR led to changes in guard and subsidiary cells, and the stomata and papillae were with irregular shape. The reduction of epicuticular wax that covered the leaf, was observed. Taken together, these findings strongly suggested that PAR + UVBR negatively affects the ultrastructure and morphology and growth rates, of leaf of $O$. sativa and, in the long term, their economic viability.
\end{abstract}

Keywords: Oryza sativa; Ultraviolet Radiation-B; Histochemistry; Ultrastructure

\section{Introduction}

The stratospheric ozone layer provides natural protection against ultraviolet radiation (UVR) for all biological organisms [1]. It has been nearly three decades since the first reports about man-made changes in this protective shield caused by atmospheric pollutants, such as chlorofluorocarbons (CFCs), halocarbons, carbon dioxide $\left(\mathrm{CO}_{2}\right)$, and methyl chloroform (MCF) [2]. As a consequence of ozone layer depletion, ultraviolet $\mathrm{B}$ radiation (UVBR) $(280-320 \mathrm{~nm})$ is increasingly reaching the Earth's surface [3]. Ultraviolet energy induces photoinhibition and photodamage in proteins, nucleic acids, and other compounds in biological tissues [3] as well as alteration in cellular ultrastructures [4].

Ultraviolet radiation affects all biological organisms in many important ways. Several studies have shown a decreased growth rate [4-6]. The photosynthetic process is also potentially affected by inhibiting the activity of the

\footnotetext{
"The authors declare that they have no conflict of interest.

"Corresponding author.
}

1,5 di-phosphate carboxylase/oxygenase (Rubisco) D1 protein of the photosystem II reaction center [7] and by altering the thylakoid membrane composition of chloroplasts [8]. In Arabidopsis thaliana [9], Oriza sativa [10], Avena fatura and Selaria vulgaris [11] changes in leaf area, as well as decreases in stomatal density after exposure to ultraviolet radiation-B, were observed.

Finally, some papers have reported changes in the ultrastructure of plants and macroalgae exposed to UVBR [4-6,8,12-15]. These changes mainly occur in the chloroplasts, altering the quantity, size, organization, and number of thylakoids [16].

Rice (Oryza sativa) is one of the most cultivated cereals in the world, along with corn and wheat, representing over $50 \%$ of agricultural production. In Latin America, Brazil is the largest producer of cereal, accounting for approximately $88 \%$ of the MERCOSUR [17]. Thus, in this study, we comparatively analyzed the responses of leaf of $O$. sativa samples under ambient conditions, PAR, and PAR + UVBR treatment, focusing on changes in cellular architecture, ultrastructure, and histochemistry. 


\section{Materials and Methods}

\subsection{Seed Plants}

The rice (Oryza sativa) seeds from cultivar EPAGRI 108 (Empresa de Pesquisa Agropecuária e Extensão Rural de Santa Catarina, Brazil) (E108) was provided by Vitorino Cooperative (Tubarão, Santa Catarina, Brazil).

\subsection{Plant Culture Conditions}

The seeds were cultivated in Plant Cell Biology Laboratory (Federal University of Santa Catarina, Florianopolis, Santa Catarina, Brazil). The seeds $(n=200)$ were cultivated in plastic trays and were soaked in were kept between thick layers of cotton cloth and water at $23^{\circ} \mathrm{C}$ (Figure 1(A)). After the germination, the seedlings $(\mathrm{n}=$ 50 per treatment) were cultivated in plastic trays with a mixture of vermiculite and fertilized soil (Figure 1(B)), and with one centimer of water depth (Figure 1(C)).

Culture room conditions were $23^{\circ} \mathrm{C}$, illumination from above with fluorescent lamps (Philips C-5 Super 84 $16 \mathrm{~W} / 840$, Brazil), photosynthetically active radiation (PAR) at $75 \mu \mathrm{mol} \cdot$ photons $\cdot \mathrm{m}^{-2} \cdot \mathrm{s}^{-1}$ (Li-cor light meter $250, \mathrm{USA}$ ) and $12 \mathrm{~h}$ photocycle (starting at $8 \mathrm{~h}$ ) for PAR treatment. UVBR was provided through a Phillips Ultraviolet-B (TL 20W/12 RS, Netherlands). The intensity of UVBR treatment was $0.60 \mathrm{~W} \cdot \mathrm{m}^{-2}$ (Radiometer Model IL
1400 A, International Light, Newburyport, MA, USA) and plants were exposed to PAR + UVBR from 12:00 to 14:00 during 30 days. To avoid exposure to UVC radiation, a cellulose diacetate foil $0.075 \mathrm{~mm}$ thick was utilized.

In the laboratory, PAR treatment were evaluated using only PAR and UVBR treatment were cultivated under PAR + UVBR. In the field, ambient samples were cultivated in shade house receiving natural radiation. The third leaf was used for light and electron microscopy was fixed directly on day 30 (Figures 2(A)-(C)), the last day of experimentation, after the final exposure to UVB at 14 h.

\subsection{Light Microscope (LM)}

Samples approximately $5 \mathrm{~mm}$ in length were fixed in $2.5 \%$ paraformaldehyde in $0.1 \mathrm{M}(\mathrm{pH}$ 7.2) phosphate buffer overnight. Subsequently, the samples were dehydrated in increasing series of ethanol aqueous solutions. After dehydration, the samples were infiltrated with Historesin (Leica Historesin, Heidelberg, Germany). Sections $5 \mu \mathrm{m}$ in length were stained with different histochemical techniques and investigated with an Epifluorescent microscope (Olympus BX 41) equipped with Image Q Capture Pro 5.1 Software (Qimaging Corporation, Austin, TX, USA).
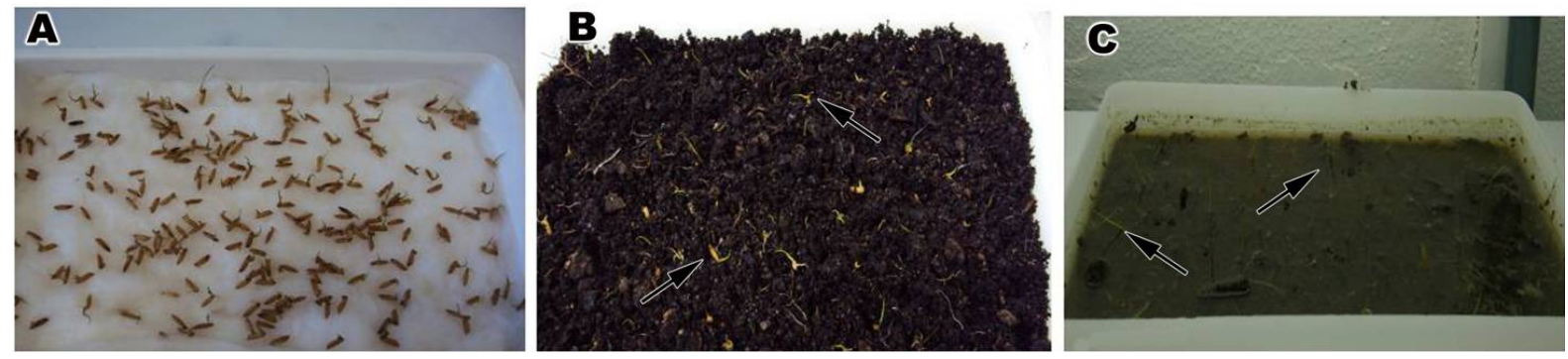

Figure 1. Detail of seeds of Oriza sativa cultivated in plastic trays. (A) Seeds cultivated in cotton; (B) and (C) Note the seedlings (arrows) cultivated vermiculite, fertilized soil and with water.

Ambient samples

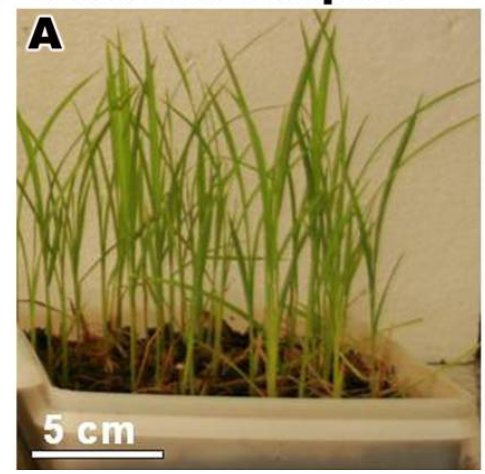

PAR-only

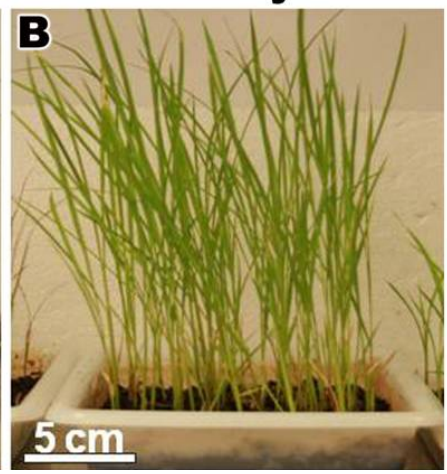

PAR+UVBR

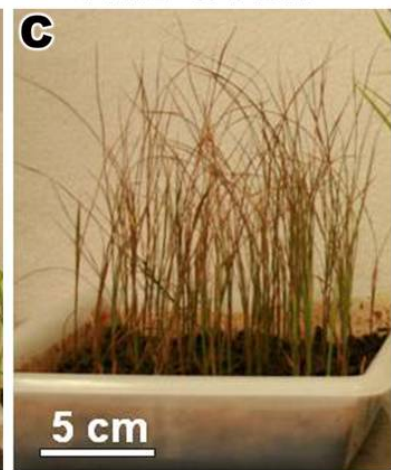

Figure 2. Plants of Oriza sativa cultivated in plastic trays during 30 days. Note the large leaves. (A) Ambient samples; (B) Plants exposed to PAR-only; (C) Plants exposed to PAR + UVBR. 


\subsection{Histochemical Staining}

LM sections were stained as follows: Periodic AcidSchiff (PAS) used to identify neutral polysaccharides [4], Toluidine Blue (TB-O) 0.5\%, pH 3.0 (Merck Darmstadt, Germany) used for acid polysaccharides through a metachromatic reaction [6], and Coomassie Brilliant Blue (CBB) $0.02 \%$ in Clarke's solution (Serva, Heidelberg, Germany) used for proteins [4]. Controls consisted of applying solutions to sections without the staining component (e.g., omission of periodic acid application in the PAS reaction).

\subsection{Transmission Electron Microscope (TEM)}

For observation under the transmission electron microscope (TEM), samples approximately $5 \mathrm{~mm}$ in length were fixed with $2.5 \%$ glutaraldehyde in $0.1 \mathrm{M}$ sodium cacodylate buffer ( $\mathrm{pH}$ 7.2) plus $0.2 \mathrm{M}$ sucrose overnight [8]. The material was post-fixed with $1 \%$ osmium tetroxide for 4 hours, dehydrated in a graded acetone series and embedded in Spurr's resin. Thin sections were stained with aqueous uranyl acetate followed by lead citrate. Four replicates were made for each experimental group; two samples per replication were then examined under TEM JEM 1011 (JEOL Ltd., Tokyo, Japan, at $80 \mathrm{kV}$ ). Similarities based on the comparison of individual treatments with replicates suggested that the ultrastructural analyses were reliable.

\subsection{Scanning Electron Microscope (SEM)}

The samples were fixed for SEM observations using procedures identical to those used for TEM. The samples were dehydrated with ethanol series, dried on Critical point EM-CPD-030 (Leica, Heidelberg, Germany), then sputter-coated with gold prior to exanimation. The samples were examined under SEM JSM 6390 LV (JEOL Ltd., Tokyo, Japan, at $10 \mathrm{kV}$ ).

\subsection{Data Analysis}

Data were analyzed by unifactorial Analysis of Variance (ANOVA) and the Tukey a posteriori test. Unifactorial statistical analyses were performed using the Statistica software package (Release 6.0), considering $\mathrm{p} \leq 0.05$.

\section{Results}

\subsection{Morphology of Leaves of Oryza sativa}

After 30 days of the experiment, the expanded leaves of Oryza sativa showed different height and length (leaf index) (Figures 3(A)-(C)). A highly significant increase in plant height and length was observed, with plants exposed to PAR-only (Figure 3(B)). Exposure to ambient reduced plant height and length compared with PARonly (Figure 3(A)) and whereas those of plants exposed to PAR + UVBR were severely shortened (Figure 3(C)). The plant growth characteristics are shown in Table 1.
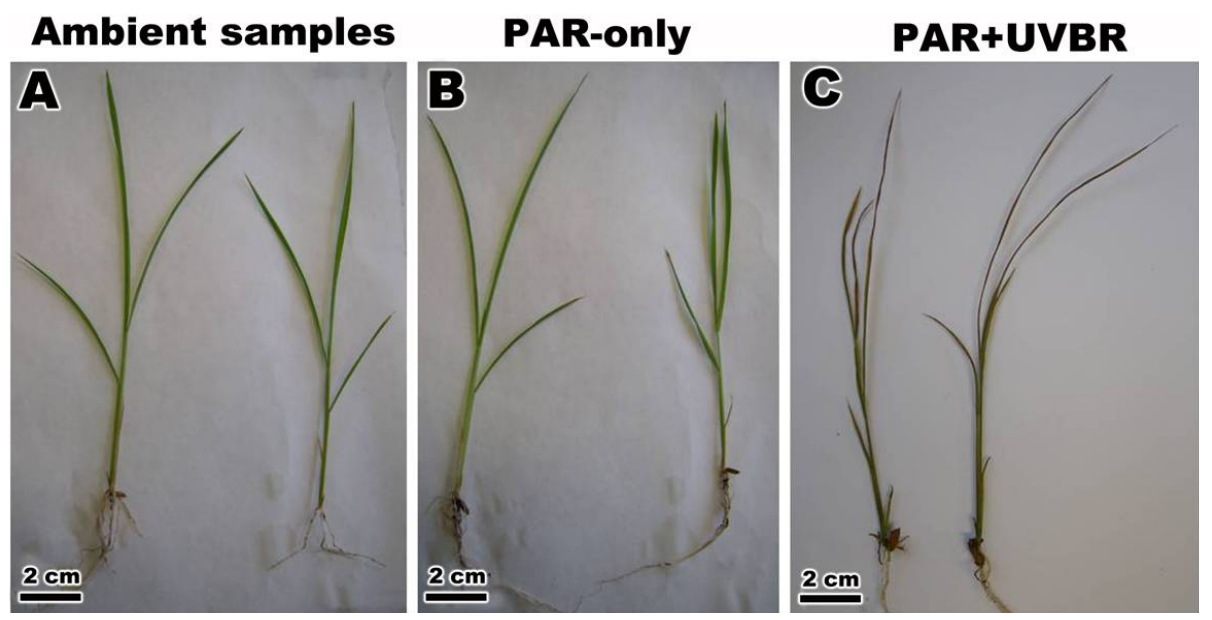

Figure 3. Morphological response of leaf of Oriza sativa after 30 days under differents light treatments. (A) and (B) Observed the expanded leaf in ambient samples and PAR-only; (C) Note the change in leaf morphology after exposure to PAR + UVBR.

Table 1. Effects of radiation on plant parameters of Oryza sativa (ambient samples, PAR-only and PAR + UVBR). Means \pm $\mathrm{S} . \mathrm{D}, \mathrm{n}=\mathbf{2 0}$ leaves. Letters indicate significant differences according to the Tukey test $(\mathbf{p} \leq \mathbf{0 . 0 5})$.

\begin{tabular}{cccc}
\hline Parameter & Ambient samples & PAR-only & PAR + UVBR \\
\hline Leaf index $(\mathrm{h} / \mathrm{l})$ & $24.9( \pm) 0.86 \mathbf{b}$ & $36.2( \pm) 1.19 \mathbf{a}$ & $20.7( \pm) 1.3 \mathbf{c}$ \\
Leaf area $\left(\mathrm{cm}^{2}\right)$ & $6.9( \pm) 0.25 \mathbf{b}$ & $8.4( \pm) 0.30 \mathbf{a}$ & $2.3( \pm) 0.12 \mathbf{c}$ \\
\hline
\end{tabular}




\subsection{Observation under Light Microscope and Histochemical}

The transversal sections of epidermal cells of the ambient samples, PAR-only and PAR + UVBR of O. sativa, when staining with TB-O, showing a metachromatic reaction in the cell wall, indicating the presence of acidic polysaccharides (Figures 4(A)-(C)). Orthochromatic reaction was observed in mesophyll cells (Figures 4(A)(C)). However in mesophyll cells of plants treated with PAR + UVBR was observed the presence of phenolic compounds (Figure 4(C)). When stained with PAS the ambient samples, PAR-only and PAR + UVBR exhibited a strong reaction, suggesting the presence of cellulosic compounds in the cell wall (Figures 4(D)-(F)). The ambient samples showed PAS-positive reaction in the cytoplasm with neutral polysaccharides, especially with many starch grains (Figure 4(D)). Nevertheless, the PAR-only and PAR + UVBR showed few starch grains (Figures 4(E) and (F)). Finally, the ambient samples, PAR-only and PAR + UVBR stained with CBB showed a positive reaction indicating the presence numerous organelles rich in protein (Figures 4(G)-(I)). In the three histochemical utilized was possible observe presence of phenolic com- pounds in the plants submitted to PAR + UVBR (Figures 4(C), (F) and (I)).

\subsection{Observation under Transmission Electron Microscope (TEM)}

When observed by TEM, the mesophyll cells of ambient samples and PAR-only (Figures 5(A)-(H)) of $O$. sativa is filled with chloroplasts, nuclei and mitochondria in the vicinity of chloroplasts (Figure 5(A)). These cells were surrounded by a primary cell wall, thin, formed by cellulose microfibrils embedded in an amorphous matrix (hemicellulose and pectin) (Figure 5(B)). Various plasmodesmata was observed connected these cells (Figure 5(C)). The chloroplast was large, surrounded by a double membrane, and had a typical well-developed grana and stromal thylakoids which generally oriented parallel to the long axis of the plastid (Figures 5(D) and (E)). The compact stroma contained few starch grains (Figures 5(B),(D) and (E)). In the chloroplasts of these cells, a small plastoglobuli were observed between the thylakoids (Figure 5(D)). In the cytoplasm also verificated mitochondria with well developed cristae membranes and rough endoplasmic reticulum (Figure 5(F)).
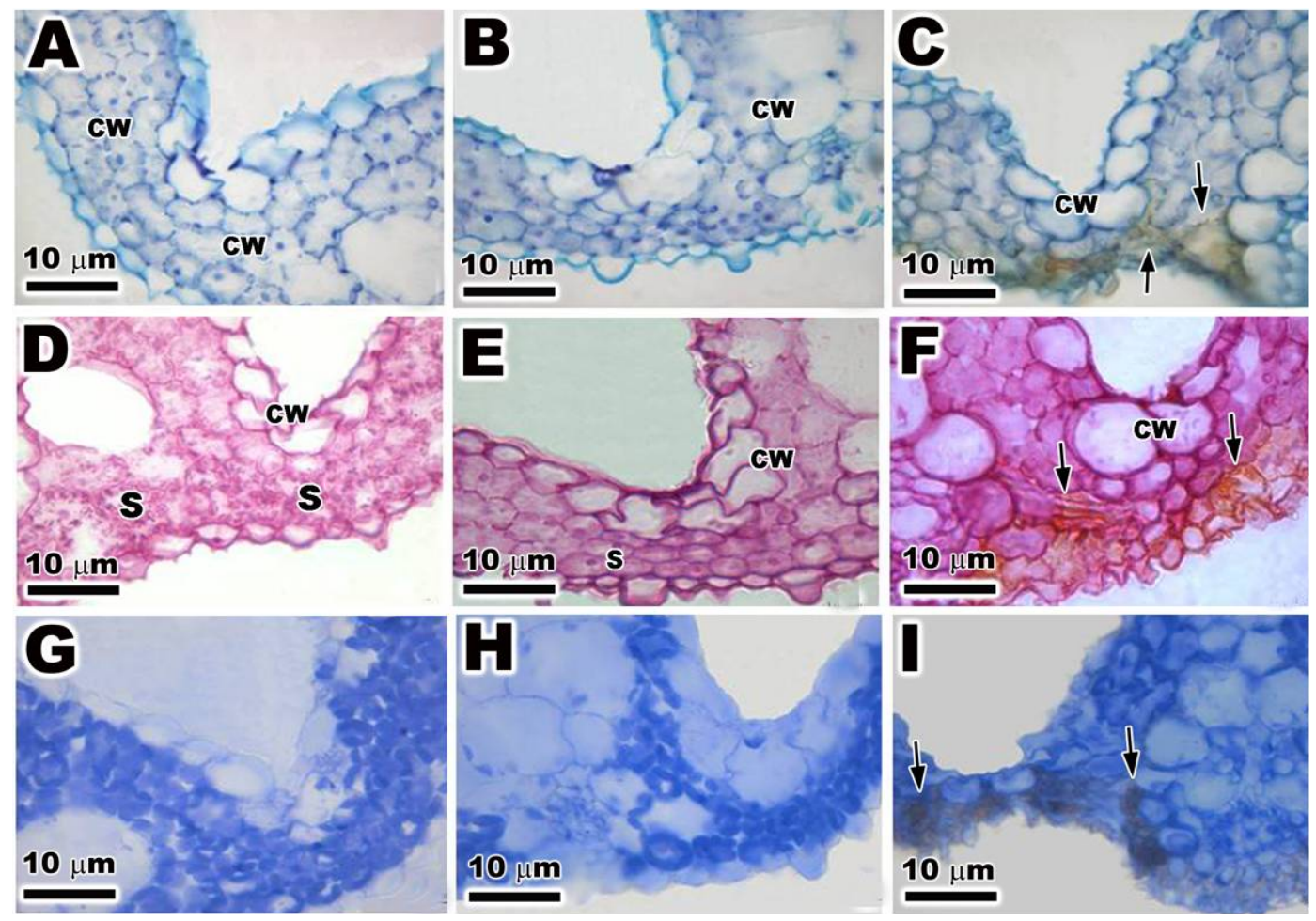

Figure 4. Light microscopy (LM) of the transversal sections of leaf of Oriza sativa after 30 days under differents light treatments. Sections stained with TB-O. (A) and (B) The cell wall shows metachromatic reaction (CW); (C) Note the presence of phenolic compounds (arrows) near the cell wall. Sections stained with PAS; (D) and (E) Observe the positive reaction in the cell wall and with starch grains (S); (F) Note the presence of phenolic compounds (arrows). Sections stained with CBB; (G) and $(\mathrm{H})$ Note the positive reaction with numerous organelles rich in protein; (I) Observe the positive reaction with numerous organelles rich in protein and the phenolics compounds (arrows). 

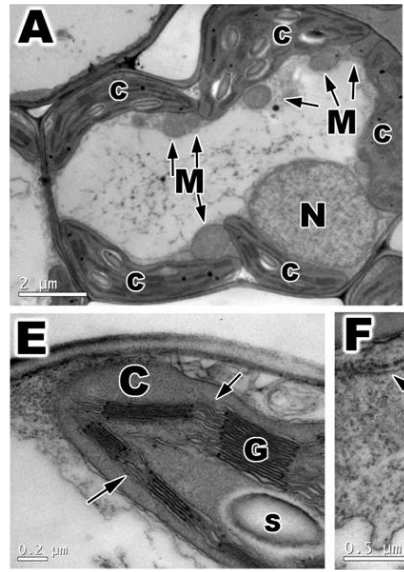
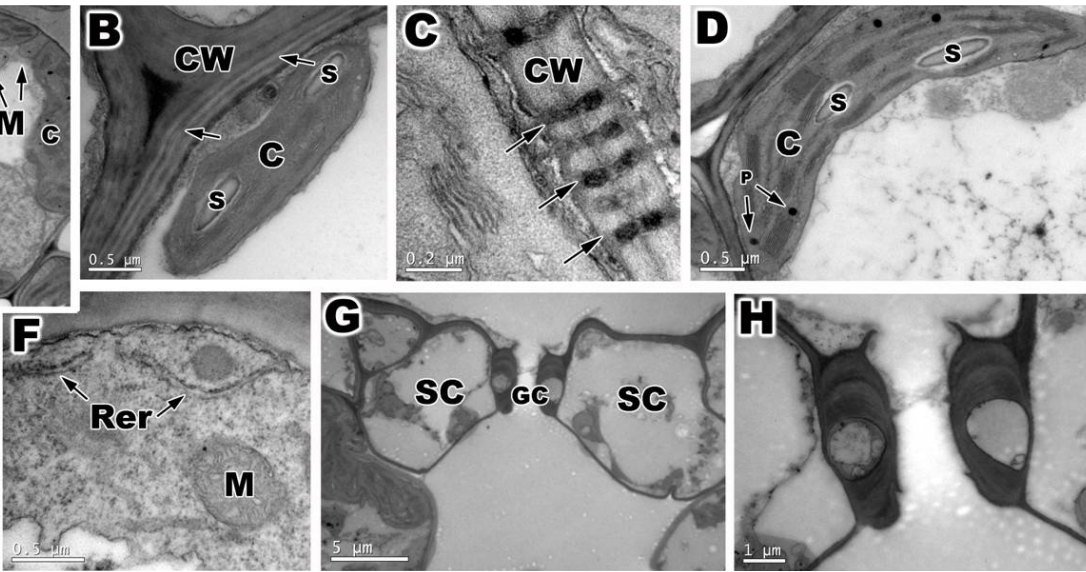

Figure 5. Transmission electron microscopy (TEM) of ambient samples and PAR-only of leaf of Oriza sativa after 30 days under differents light treatments. (A) Overview of mesophyll cells. Note the large quantity of chloroplasts (C) and mitochondria (M), and the nuclei $(\mathrm{N})$; $(\mathrm{B})$ Detail of primary cell wall $(\mathrm{CW})$, with lamellae media (arrows). Note the chloroplast with starch grains (S); (C) Note the plasmodesmata (arrows); (D) Observe the chloroplast with plastoglobuli (P) and starch grains; (E) Detail of chloroplast with well developed grana (G) and stromal thylakoids (arrows); (F) Note the presence of rough reticulum endoplasmatic (Rer) and mitochondria with cristae membrane; (G) Stomata complex with a guard cells (GC) and subsidiary cells SC); (H) Magnification of previous figures showing detail of guard cells.

The abbatial leaf surface of $O$. sativa is covered by stomata, part of a stoma complex consisting of a pore surrounded on each side by chloroplast-containing two guard cells, and two subsidiary cells that lack chloroplasts (Figures 5(G) and (H)).

However, after a daily 2-hour exposure to PAR + UVBR for a 30-day period, $O$. sativa showed ultrastructural changes involving modifications, especially in cell wall, chloroplasts, and mitochondria and in the guard cells (Figures 6(A)-(I)). The cell wall became more compact in irradiated plants (Figure 6(B)), also observed the presence of phenolic compounds near the cell wall (Figures 6(C) and (D)). The chloroplasts showed more visible changes in ultrastructural organization with irregular morphology (Figures 6(E) and (F)). The thylakoids were disrupted and swollen (Figures $\mathbf{6}(\mathbf{E})$ and $(\mathbf{F})$ ), and the number of plastoglobuli was increased in the chloroplasts (Figure 6(F)). Mitochondria appeared to be disrupted and irregular in shape (Figure 6(G)). The guard and subsidiary cells were with irregular shape (Figures $\mathbf{6}(\mathbf{H})$ and (I)).

\subsection{Observation under Scanning Electron Microscope (SEM)}

Under SEM the abbatial surface of ambient samples (Figure 7(A)) and PAR-only (Figure 7(B)) of the leaf of $O$. sativa was possible observe detail of stomata and ostiole. The stoma was covered with epicuticular wax and a large quantity of papillae. The plants treated with PAR + UVBR the stomata and papillae appeared with irregular shape and reduction of epicuticular wax was observed (Figure 7(C)).

\section{Discussion}

The present study showed that the leaf of Oriza sativa was affected by PAR + UVBR which induced changes in leaf morphology, plant biomass, in chloroplast and mitochondria organization, as well increasing cell wall thickness and disrupted the stomata structure. The exposure to PAR + UVBR led to reduction in plant biomass, altered guard cells and leaf area of $O$. sativa, similar results were observed in Pisum sativum [17,18] and Brassica napus [19]. This reduction in treated plants of $O$. sativa could be related with changes in cell expansion and turgor pressure [17].

When analyzed under LM, the PAR + UVBR treated plants showed a presence of phenolic compounds in three different histochemical. According to Ruhland et al. [20] and Schmidt et al., [14] the increased concentrations of phenolic compounds in response to elevated radiation have two different functions: 1) To act as a sunscreen against potentially damaging UVB and 2) To ameliorate damage caused by increased ROS. According to [21], the phenolic compounds could act as a photoprotection mechanism against higher irradiance in the ecosystems by absorbing incident photons or indirectly as a result of their antioxidant activity.

After exposure to PAR + UVBR the leaf of $O$. sativa showed the increase in primary cell wall structure and more compact in irradiated plants. The increase in the thickness of the cell wall of $O$. sativa exposed to PAR + UVBR can be interpreted as a defense mechanism against exposure to ultraviolet radiation. Such increase in cell wall thickness can be interpreted as a defense mechanism 

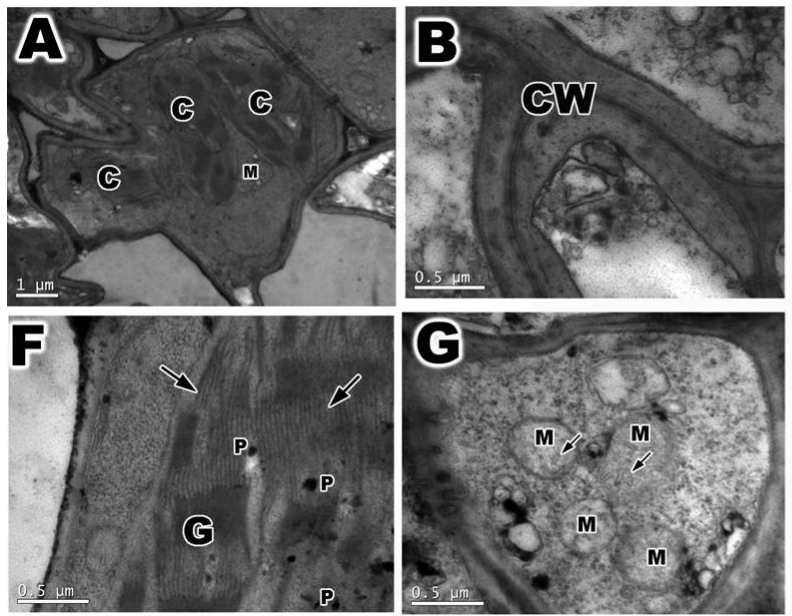

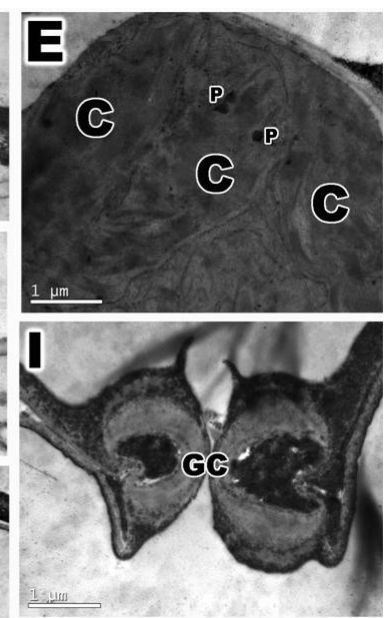

Figure 6. Transmission electron microscopy (TEM) of samples treated with PAR + UVBR of leaf of Oriza sativa. (A) Detail of mesophyll cells with irregular shape; (B) Note the thick cell wall and with compact aspect; (C) and (D) Observe the presence of phenolic compounds in the cell wall (arrows); (E) Note the irregular chloroplast morphology with swollen thylakoids (arrows) and large quantity of plastoglobuli; (F) Detail of disrupted mitochondria with cristae dilatation; (G) and (H) Note the guard cells with modification after exposure to PAR + UVBR.
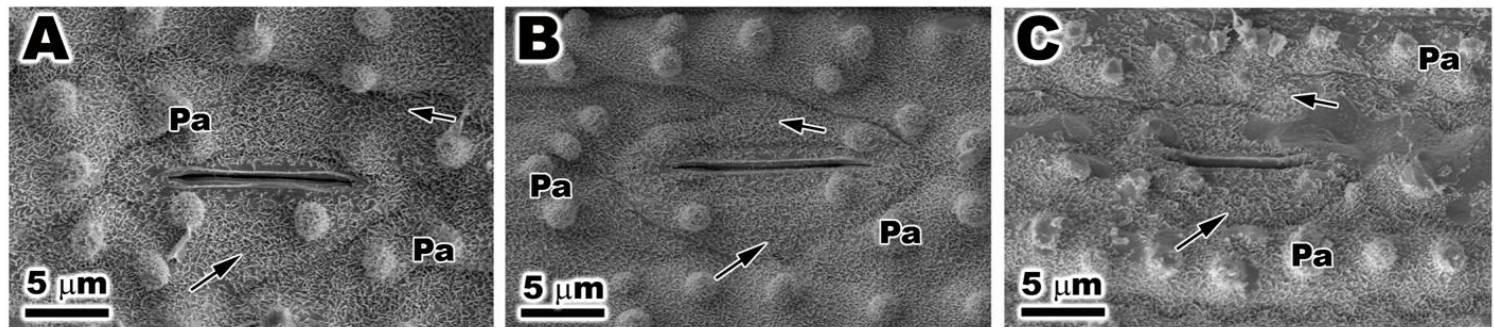

Figure 7. Scanning electron microscopy (SEM) of leaf of Oriza sativa after 30 days under differents light treatments. (A) and (B) Note the presence of epicuticular wax (arrows) and papillae; (C) Observe the reduction in epicuticular wax (arrows), and the irregular outline of stomata and papillae.

against exposure to ultraviolet radiation. According to Hóllosy [13], for example, an increase in thickness was specifically interpreted as a protective mechanism against damage caused by UV radiation. Moreover, other cellular and morphological changes have been reported as a defense mechanism against UVBR. Staxén and Bornman [22] reported the alteration of the deposition of cell wall microfibrils. Microtubules, which have been implicated in the deposition of cell wall microfibrils, depolymerized when irradiated by UVB, and the disruption of the cortical microtubule network of epidermal cells could result in altered cell shape and, consequently, altered leaf morphology

Our results showed that ambient samples and PARonly of O. sativa had a typical chloroplast with welldeveloped grana and stromal thylakoids which generally oriented parallel to the long axis of the plastid. In contrast, the chloroplasts of $O$. sativa exposed to PAR + UVBR showed significant structural changes, including disrupted and swollen thylakoids. Studies with different important macroalgae exposed to PAR + UVBR including
Kappaphycus alvarezii [4-6], Gracilaria domingensis [23], Chondracanthus teedei [8] and Hypnea musciformis [14] also showed ultrastructural changes in chloroplasts which manifest as dilation and disorganization of thylakoids.

Photosystem II (PSII) is a major target of UVBR in photosynthetic organisms [24-26]. Since it would be difficult to establish a proton gradient across the thylakoid membrane under UVBR radiation, photosynthetic reactions will be impaired [27]. Other reports of UVBR-induced changes include the depolarization of membrane potential, net leakage of $\mathrm{Cl}^{-}, \mathrm{Na}^{+}$and $\mathrm{K}^{+}$, and different ATPase activities in cell membranes [28-30] and in thylakoid membranes [31-33].

When analyzed by TEM, the exposed to PAR + UVBR of $O$. sativa revealed an increase in the number of the plastoglobuli in the chloroplast. According to Holzinger et al., [34], when the algae are subjected to stress, nitrogen limitation and the synthesis of lipids are observed. These phenomena occur because the pathways to form protein-containing cell structures are suppressed.

The mitochondria of the PAR + UVBR of O. sativa 
also showed ultrastructural changes. The mitochondria appeared swollen, and the inner mitochondrial membrane was disrupted. Other studies report ultrastructural changes in mitochondria of Gr. domingensis Schmidt et al. [23] and C. teedei Schmidt et al., [8], these changes were manifested by an apparent swelling and by changes in the inner mitochondrial membrane from a tubuli- to sacculi-type structure when exposed to PAR + UVBR, mitochondria appeared swollen, and the presence of electron-dense granules in the mitochondrial matrix was detected. Such ultrastructural changes can result in a disordered metabolism of ATP [35].

\section{Acknowledgements}

The authors would like to acknowledge the staff of the Central Laboratory of Electron Microscopy (LCME), Federal University of Santa Catarina, Florianopolis, Santa Catarina, Brazil, for the use of their transmission and scanning electron microscope. Éder C. Schmidt holds a postdoctoral fellowship from CAPES. Zenilda L. Bouzon is CNPq fellows. This study is part of the Ph.D. thesis of the first author.

\section{REFERENCES}

[1] S. Madronich, "Implications of Recent Total Atmospheric Ozone Measurements for Biological Active Ultraviolet Radiation Reaching the Earths Surface," Geophyscal Research Letters, Vol. 19, No. 1, 1992, pp. 37-40. doi:10.1029/91GL02954

[2] J. B. Kerr and C. T. M. Elroy, "Evidence for Large Upward Trends of Ultraviolet-B Radiation Linked to Ozone Depletion," Science, Vol. 262, No. 5136, 1993, pp. 10321034. doi: $10.1126 /$ science. 262.5136 .1032

[3] D. L. Mitchell, J. Jen and J. E. Cleaver, "Sequence Specificity of Cyclobutane Pyrimidine Dimers in DNA Treated with Solar (Ultraviolet B) Radiation," Nucleic Acids Research, Vol. 20, No. 2, 1992, pp. 225-229.

[4] É. C. Schmidt, T. Rover, L. Scariot and Z. L. Bouzon, "Changes in Ultrastructure and Histochemistry of Two Red Macroalgae Strains of Kappaphycus alvarezii (Rhodophyta, Gigartinales), as a Consequence of Ultraviolet B Radiation Exposure," Micron, Vol. 40, No. 8, 2009, pp. 860-869. doi:10.1016/j.micron.2009.06.003

[5] É. C. Schmidt, M. Maraschin and Z. L. Bouzon, "Effects of UVB Radiation on the Carragenophyte Kappaphycus alvarezii (Rhodophyta, Gigartinales): Changes in Ultrastructure, Growth, and Photosynthetic Pigments," Hydrobiologia, Vol. 649, No. 1, 2010, pp. 171-182. doi:10.1007/s10750-010-0243-6

[6] É. C. Schmidt and B. N. Gomes, M. Maraschin and Z. L. Bouzon, "Effect of Ultraviolet-B Radiation on Growth, Photosynthetic Pigments, and Cell Biology of Kappaphycus alvarezii (Rhodophyta, Gigartinales) Macroalgae Brown Strain," Photosynthetica, Vol. 48, No. 2, 2010, pp. 161-172. doi:10.1007/s11099-010-0022-7
[7] M. P. Lesser and J. M. Shick, "Effects of Irradiance and Ultraviolet Radiation on Photoadaptation in the Zooxanthellae of Aiptasia pallida: Primary Production, Photoinhibition, and Enzymic Defenses against Oxygen Toxicity," Marine Biology, Vol. 102, 1994, pp. 243-255.

[8] É. C. Schmidt, B. Pereira, R. Santos, C. L. M. Pontes, F. Scherner, P. A. Horta, M. R. Paula, A. Latini, F. Ramlov, M. Maraschin and Z. L. Bouzon, "Alterations in Architecture and Metabolism Induced by Ultraviolet Radiation-B in the Carragenophyte Chondracanthus teedei (Rhodophyta, Gigartinales)," Protoplasma, Vol. 249, No. 2, 2012, pp. 353-367.

[9] M. R. T. Boeger and M. Pulson, "Efeitos da Radiação U1travioleta-B Sobre a Morfologia Foliar de Arabidopsis thaliana (L.) Heynh. (Brassicaceae)," Acta Botanica Brailicas, Vol. 20, 2006, pp. 329-338.

[10] Q. Dai, S. Peng, A. Q. Chavez and B. S. Vergara, "Effects of UV-B Radiation on Stomatal Density and Opening in Rice (Oryza sativa L.)," Annals of Botany, Vol. 76, No. 1, 1995, pp. 65-70. doi:10.1006/anbo.1995.1079

[11] K. Zuk-Golaszewska, M. K. Upadhyaya and J. Golaszewski, "The Effect of UV-B Radiation on Plant Growth and Development," Plant, Soil and Environment, Vol. 49 No. 3, 2003, pp. 135-140.

[12] M. M. Cassi-Lit, J. Whitecross, M. Nayudu and G. J. Tanner, "UV-B Radiation Induces Differential Leaf Damage, Ultra Structural Changes and Accumulation of Specific Phenolic Compounds in Rice Cultivars," Australian Journal Plant Physiology, Vol. 24, No. 3, 1997, pp. 261274. doi:10.1071/PP96080

[13] F. Hóllosy, "Effects of Ultraviolet Radiation on Plant Cells," Micron, Vol. 33, No. 2, 2002, pp. 179-197.

[14] É. C. Schmidt, B. Pereira, R. Santos, C. Gouveia, G. B. Costa, G. S. M. Faria, F. Scherner, P. A. Horta, M. R. Paula, A. Latini, F. Ramlov, M. Maraschin and Z. L. Bouzon, "Responses of the Macroalgae Hypnea Musciformis after in Vitro Exposure to UV-B," Aquatic Botany, Vol. 100, 2012, pp. 8-17. doi:10.1016/j.aquabot.2012.03.004

[15] S. H. Sarghein, J. Carapetian and J. Khara, "The Effects of UV Radiation on Some Structural and Ultrastructural Parameters in Pepper (Capsicum longum A.DC.)," Turkish Journal Biology, Vol. 35, No. 1, 2011, pp. 69-77.

[16] L. Talarico and G. Maranzana, "Light and Adaptative Responses in Red Macroalgae: An Overview," Journal of Photochemistry and Photobiology B: Biology, Vol. 56, No. 1, 2000, pp. 1-11. doi:10.1016/S1011-1344(00)00046-4

[17] S. Nogue's, D. J. Allen, J. I. L. Morison and N. R. Baker, "Ultraviolet-B Radiation Effects on Water Relations, Leaf Development and Photosynthesis in Droughted Pea Plants," Plant Physiology, Vol. 117, No. 1, 1998, pp. 173-181. doi:10.1104/pp.117.1.173

[18] R. Gonzalez, R. Mepsted, A. R. Wellburn and N. D. Paul, "Non-Photosynthetic Mechanisms of Growth Reduction in Pea (Pisum sativum) Exposed to UV-B Radiation," Plant Cell and Environment, Vol. 21, No. 1, 1998, pp. 23-32. doi:10.1046/j.1365-3040.1998.00243.x

[19] C. M. Alenius, T. C. Vogelmann and J. F. Bornman, “A Three-Dimensional Representation of the Relationship be- 
tween Penetration of UV-B Radiation and UV-Screening Pigments in Leaves of Brassica napus," New Phytologist, Vol. 131, No. 3, 1995, pp. 297-302. doi:10.1111/j.1469-8137.1995.tb03065.x

[20] C. T. Ruhland, M. J. Fogal, C. R. Buyarski and M. Krna, "Solar Ultraviolet-B Radiation Increases Phenolic Content and Ferric Reducing Antioxidant Power in Avena sativa," Molecules, Vol. 12, No. 6, 2007, pp. 1220-1232. doi:10.3390/12061220

[21] R. T. Abdala-Díaz, A. Cabello-Pasini, E. Pérez-Rodríguez, R. M. C. Álvarez and F. L. Figueroa, "Daily and Seasonal Variations of Optimum Quantum Yield and Phenolic Compounds in Cystoseira tamariscifolia (Phaeophyta)," Marine Biology, Vol. 148, No. 3, 2006, pp. 459-465. doi:10.1007/s00227-005-0102-6

[22] I. Staxén and J. F. Bornman, "A Morphological and Cytological Study of Petunia hybrida Exposed to UV-B Radiation," Physiologia Plantarum, Vol. 91, No. 4, 1994, pp. 735-740. doi:10.1111/j.1399-3054.1994.tb03013.x

[23] É. C. Schmidt, R. Santos, P. A. Horta, M. Maraschin and Z. L. Bouzon, "Effects of UVB Radiation on the Agarophyte Gracilaria domingensis (Rhodophyta, Gracilariales): Changes in Cell Organization, Growth and Photosynthetic Performance," Micron, Vol. 41, No. 8, 2010, pp. 919-930. doi:10.1016/j.micron.2010.07.010

[24] A. Post, S. Gentle and A. W. S. Larkum, "Algal Photosynthesis: Inhibition by UV-B Radiation, Recovery and UV-Absorbing Pigments," In: N. Murata, Ed., Research in Photosynthesis, Kluwer Academic Publishing, London, 1992, pp. 847-850.

[25] P. J. Neale, J. C. Cullen, M. P. Lesser and A. Melis, "Physiological Bases for Detecting and Predicting Photoinhibition of Aquatic Photosynthesis by PAR and UV Radiation," In: H. Y. Yamamoto and C. M. Smith, Eds., Photosynthetic Responses to the Environment, American Society of Plant Biologists, Rockville, 1993, pp. 61-77.

[26] I. Vass, "Adverse Effects of UV-B Light on the Structure and Function of the Photosynthetic Apparatus," Handbook of Photosynthesis, Marcel Dekker, New York, 1997.

[27] F. Poppe, R. A. M. Schmidt, D. Hanelt and C. Wiencke,
"Effects of UV Radiation on the Ultrastructure of Several Red Algae," Phycological Research, Vol. 51, No. 1, 2003, pp. 11-19.

[28] C. J. Doughty and A. B. Hope, "Effects of Ultraviolet Radiation on the Membranes of Chara coralline," Journal of Membrane Biology, Vol. 13, No. 1, 1973, pp. 185-198. doi:10.1007/BF01868227

[29] T. M. Murphy, "Membranes as Targets of Ultraviolet Radiation," Physiologia Plantarum, Vol. 58, No. 3, 1983, pp. 381-388. doi:10.1111/j.1399-3054.1983.tb04198.x

[30] R. L. Gallo, I. E. Kochevar and R. D. Granstein, "Ultraviolet Radiation Induces a Change in Cell Membrane Potential in Vitro: A Possible Signal for Ultraviolet Radiation Induced Alteration in Cell Activity," Photochemistry and Photobiology, Vol. 49, No. 5, 1989, pp. 655-662. doi:10.1111/j.1751-1097.1989.tb08438.x

[31] W. Iwanzik, M. Tevini, G. Dohnt, M. Voss, W. Weiss, P. Gräber and G. Renger, "Action of UV-B Radiation on Photosynthetic Primary Reactions in Spinach Chloroplasts," Physiologia Plantarum, Vol. 58, No. 3, 1983, pp. 401407. doi:10.1111/j.1399-3054.1983.tb04201.x

[32] W. S. Chow, A. Strid and J. M. Anderson, "Short-Term Treatment of Pea Plants with Supplementary UltravioletB Radiation: Recovery Time-Courses of Some Photosynthetic Functions and Components," In: N. Murata, Ed., Research in Photosynthesis, Kluwer Academic Publishing, Dordrecht, 1992, pp. 361-364.

[33] E. Hideg and I. Vass, "UV-B Induced Free Radical Production in Plant Leaves and Isolated Thylakoid Membranes," Plant Science, Vol. 115, No. 2, 1996, pp. 251260. doi:10.1016/0168-9452(96)04364-6

[34] A. Holzinger, M. Y. Roleda and C. Lütz, "The Vegetative Arctic Freshwater Green Alga Zygnema Is Insensitive to Experimental UV Exposure," Micron, Vol. 40, No. 8, 2009, pp. 831-838. doi:10.1016/j.micron.2009.06.008

[35] J. Vosjan, H. Döhler and G. Nieuwland, "Effect of UV-B Irradiance on the ATP Content of Microorganisms of the Weddell sea (Antarctica)," Netherlands Journal of Sea Research, Vol. 25, No. 3, 1990, pp. 391-394. doi:10.1016/0077-7579(90)90046-J 